\section{THE OPERATIVE TREATMENT OF CONGENITAL} CATARACT.

BY ANDERSON CRITCHETT, M.A.Cantab., Ophthalmic Surgeon to, and Lecturer on Ophthalmic Surgery at, St. Mary's Hospital.

Although this subject has from time to time been fully, and in some respects exhaustively, discussed, I think it will be admitted that a considerable diversity of opinion still exists as to the period of life when operative measures become not only justifiable, but expedient, and also as to the form of operation which should be adopted in any given case. The youth of the patient, the partial character of the blindness, and the exceptional risk which attends certain methods of operating that are frequently used for its relief, all combine to invest this subject with an unusual degree of interest and anxiety. My object in reviewing this question is to urge the importance of judging each case upon its individual demerits, and to enter a protest against the adoption of an uniform plan in all instances, owing to an almost universal tendency to regard a cataract as a thing to be removed by operation, without giving sufficient consideration to the amount of vision which the patient has till then possessed. I am ready to allow that we meet with a certain proportion of cases where, owing to the extent and degree of the lenticular opacity, and the consequent serious impairment of sight, it is necessary to have recourse to the more radical methods of absorption or suction. Time will not allow me to enter at any length on this important section of the subject, nor would I presume to adjudicate where so many high authorities have already pronounced their opinions. I may, however, in the first place, suggest that, owing to the risk which attaches to either of these operations, even in the most skilful hands, coupled with the fact that failure means nothing less than the blighting of a long and possibly useful life, prudence and humanity should alike forbid a simultaneous operation on both eyes. Respecting the relative merits of absorption and suction, my cwn personal experience, and my observation of the practice of others, would lead me to select the slower method by absorption; reserving the more brilliant, but, I fear I must add, more risky plan by suction, respectively advocated by $\mathrm{Mr}$. Bowman and Mr. Teale, for those exceptional cases in which the irritative effects of lenticular fragments threaten the safety of the eye and, even in such cases, a partial removal of the lens-matter by simple paracentesis will often be found equally efficacious, and accompanied by less danger.

An additional argument in favour of adopting the more cautious method by absorption is to be fourd in the fact, that no necessity exists for obtaining a rapid result, since, one eye only being dealt with, the ordinary pursuits of young life need not be suspended. But, while the above is true concerning a limited number of cases, there exist a decided majority of congenital cataracts in which the partial character of the lenticular opacity suggest an important modification in our operative procedure ; and it is to this last point that I desire, in the present paper, to direct attention. The lamellar cataract to which I am now referring is found to differ both in the density of the central opacity, and in the degree to which it encroaches on the more or less clear margin. It is, of course, difficult to lay down any hard and fast rule for adoption; but practically it will be found that, whenever the transparent margin represents one-third of the diameter of the lens, a sufficiently satisfactory result can be obtained to justify the selection of a modified form of iridectomy, or, in some isolated cases, of iridodesis. Before deciding upon either of these plans, it will be well to ascertain to what extent the vision is improved by complete mydriasis, bearing in mind that the creation of a small artificial pupil will, for obvious reasons, secure a more perfect optical result than can be obtained by the use of atropine. The object in view in altering the shape and situation of the natural pupil is to obtain an aperture opposite to the transparent margin of the lens, and corresponding, as nearly as possible, to the size of a central pupil in a moderate state of contraction. The most convenient situation for it is downwards and inwards. The method which my father has recommended, and which I generally adopt, is as follows.

An anæsthetichaving been administered, the lids are separated by a stop speculum, and the operator, steadying the globe with a pair of fixationforceps, introduces a broad needle set at an angle into the anterior chamber, being'guided as to the point of entry by the amount of iris which he desires to remove. If there be an exceptional width of clear lenticular margin, the incision may be made within the corneal area to such an extent that a portion of the peripheral circumference of the iris remains intact; but

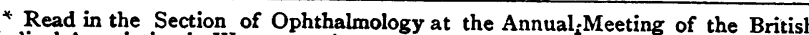
Medical Association in Worcester, August 1882. if, on the other hand, the transparent region be more limited, the pupil must extend further inwards, and this may be accomplished with considerable precision by accurately defining the position of the carneal wound. The broad needle should be introduced at an exact right angle to the cornea, so that it may enter the chamber without travelling unduly between the corneal layers. As the point of the needle is seen within the chamber, the handle of the instrument should be depressed, so as to avoid the possibility of wounding the lens. The needle should be slowly withdrawn, otherwise a rush of aqueous humour may entangle the iris in the wound. The operator then introduces a small blunt hook, known as Tyrrel's hook, also curved at an angle like the needle. The hook is passed in on the flat beyond the pupillary margin, which is caught by inclining the free edge of the hook slightly downwards. Steady traction should then be made towards the wound; but immediately before emergence the hook must be gently rotated, so that its free edge presents a little forwards, to secure an easy exit, and to prevent its entanglement in the corneal aperture. The portion of iris which has been drawn out, and is still held by the hook, should be cleanly excised with small blunt-pointed curved scissors, close to the cornea, by that much to be desired, but not always available, coadjutor, a competent assistant.

If gentle friction be then made with the upper lid over the puncture, the iris floats back into the chamber, and all the elements of a well accomplished iridotomy are secured without its palpable dangers. Nothing further is needed but a light water-dressing and a few days of rest. I may add, that the limitation in the size of the pupil which this method secures, obtains for us a better optical result than can be produced by any iridectomy performed with keratome and forceps.

As I have already stated, the practice of removing the lens in cases of congenital cataract is, I believe, the plan which is still most com. monly adopted; though I ain pleased to say that our President, Mr. Vose Solomon, spoke as follows in an inangural address which he delivered at Queen's College, Birmingham, in i876. "The plan of making an extension of the pupil by the removal of a narrow strip of iris in cases of congenital cataract, in which there is a zone of trans. parent lens, must be considered as an important advance; and where this condition of lens is binocular, I am in the habit of acting upon the method named in one eye, and destroying the other by solution." The advocates of the major operation will doubtless claim for it that cosmetically they gain a clear black central pupil, that the result is final, and that by the aid of suitable glasses, an optical condition may be anticipated which is superior to that which obtains by any other plan. The drawbacks which experience has forced upon my attention are : firstly, the serious risks involved; secondly, the disadvantage, especially to the young, of constantly wearing heavy and powerful glasses; and thirdly, as I have noted in numerous instances, the eye that has been deprived of its lens possesses a lower vitality, and is more liable to failure of its functions. I think I may fairly allege that the operation by artificial pupil has the following merits. It is one of great simplicity, and when pertormed with adequate care and skill, of almost invariable safety. The recovery is extremely rapid, and entails a very brief convalescence. The vision, though somewhat below. the most perfect results obtained by absorption, is in most instances sufficiently good for all the purposes of life, and is obtained without the aid of glasses, while the power of estimating distances is intact. The chief objection that may be urged against this plan is the possible extension of the central lenticular opacity to the margin. This may be true of certain cases which occupy an intermediate position, and where radiating striæ invade the transparent portion of the lens. Even here, however, I should not hesitate to give the patient the benefit of the doubt, and of the artificial pupil; since, in the event of a necessity arising for the major operation, we know on the high authority of Von Graefe that a preliminary iridestomy introduces a decided element of safety. I have, however, no hesitation in asserting that, where a clean and clearly defined limit exists between the central opacity and the transparent margin, the latter remains bright through life. I have seen several cases answering to the above description where more than twenty years have elapsed since my father performed on them either iridectomy or iridodesis, and where the peripheral portion of the lens has retained its absolute transparency. The converse of this has not yet come before my notice. I will not weary you with statistics of cases in confirmation of these views, though the confidence with which I have ventured to state my position is fully justified by the result of my experience in this direction at St. Mary's Hospital. I will, however, allude to one case which I brought before the Ophthalmological Society this year, and which well illustrates the relative value cf the rival operations.

Isaac G., aged eighteen, was admitted to St. Mary's Hospital on April 18th, 1882. The cataract in his right eye had been absorbed 
cight years before, and with a $+3 \frac{1}{2}$ lens he saw $5 g$, and with $a+2 \% / 2$ read No. 4 of Jaeger's test-types. He complained that, owing to the necessity for using a strong glass, he was unable to procure a situation, or to earn his living. In the left eye, where he had a lamellar cataiact, I performed a small iridectomy downwards, and inwards, with the result that he without a glass sees 8 if, and reads Jaeger 4 , and has obtained a situation as a domestic servant. I by no means claim any element of noveliy or originality for the foregoing ob. servation; ; but I have felt, and strongly feel that the merits of the particular mode of treatment which I have bere advocated, have not hitherto been generally estimated at their true value; and I venture to hope that this pian may in the future obtain a more extended trial, since I ain well assured that it deserves to supersede, in a large proportion of cases, its older and more firmly established rivals.

Mr. Cowel agrced in Mr. Critchett's suggestion, and had been in the habit of following the practice in suitable cases. He disapproved of the use of Tyrrell's hook, from a tear of wounding the lens, and used irisforceps. $\rightarrow$ Mr. NeTTLesm to the belief that cases of lamellar cataract remained stationary, but thought more observations were necessary.-The PREsIDENT had been in the habit of adopting the operation referred to by Mr. Critchett for many years with satisfactory results.

ON COLLECTIIE INVESTIGATION ; ITS AIMS AND PROBABLE INFLUENCE UPON THE FUTURE, OF THE BRITISH MEDICAL ASSOCIATION.*

BY C. PALMER, M.R.C.S., Retiring President of the Branch.

Gexirnmen, - At the close of my year of office, I thank you again most heartily for the honour you have conferred on me, and the opportunity you have thereby afforded me of becoming personally acquainted with so many of our leading men, and their views on matters of interest to our Society.

I am pleased to be able to congratulate you upon the progress we have made during the past year, not only in our own Branch, which is as prosperous as we can wish, but the British Medical Association itself, which, though fifty years old, has proved by its energy, rapid growth and development, that it still possesses all the attributes of vigorous youth. It is now scarcely eighteen months ago, that Dr. Gordon of Dublin gave the following summary of the main objects of our Association, viz. :

I. The promotion of social and scientific intercourse amongst mem. bers of the profession.

2. The maintenance of a high ethical standard of professional con. duct.

3. Encouragement of scientific and practical work, and the advancement of original investigation.

4. Improvement in medical education and examination.

And on all these points we may congratulate ourselves upon having made real and substantial progress; but, within the last few years, the conviction has been gradually gaining ground that, with all our energy and prosperity, there is a defiency somewhere; that the subjects I have just now enumerated are not the only ones which should occupy our attention; and we all began to feel that, with abundance of the best material, from a want of proper organisation, we were unable to attempt the solution of any of the great problems of disease. This want is now, for the first time, perhaps, being felt by the great body of the Association, as manifested by the enthusiastic reception of Professor Humphry's statement at Cambridge in August 1880 , that the work of collective action and cumulative observation has hitherto been too little attempted; a statement, the importance of which we can even now scarcely realise, and which led in 1881 to the formation of the Committee of Collective Investigation; a work for which we owe Professor Humphry, and his friends and advisers, a deep debt of grati. tude; for, to my mind, it is a new starting-point, the commencenient of the real work of our Society, to which what we have hitherto done has been only preliminary. The thorough elucidation of diseases, their causes and effects, immediate and remote, upon individuals, the community at large, and upun each other, is the work which we are now, tor the first time, aloout to attempt, by means which until now have never hefore been available, and to accomplish which we must be something mrre than a medical association; we must be so organiscd as to become a veritable army of observation, with a discipline so perfect, that

Read at the Anrual Meeting of the Fast Anglian Branch. every single member shall have his part to perform, and our whole force be capable of being brought to bear upon any one point, with a power that must eventually overcome erery obstacle, and in tinue re. move the stigma of uncertainty from our art, and raise it to even a higher position than it has hitherto occupied. To accomplish such results, it will not only be necessary to improve our organisation, but also to extend the field of our observation; indeed, we can already see that many points of vital importance can only be satisfactorily cleared up by an organised system of observation extended to other countries; and I venture to predict that a day will come when the British Medical Association itself will be but a branch of an international one.

There will, I have no doubt, be some amongst us who will say, as men learned in military matters said of our volunteers about twenty years ago, that, though thorough training was necessary before they could become a reliable arm of the service, it was impossible for them to attain to it; but the result has triumphantly proved that they were mistaken; and I am perfectly satisfied that when once the necessity of organisation is demonstrated and generally admitted, the rest will fol. low as a matter of course, and every one of us will not only be ready, but anxious to put our shoulders to the wheel. And if it be said that it is impossible that the bard worked general practitioner should ever spare the time for all this, we may safely reply, that the power it will give him over his own work will much more than compensate him for the loss of time it will entail.

I know that I owe you an apology for taking up so much of your time, when there is much work to be done, and little time to do it in ; but I felt that I could not let this opportunity pass, without stating as briefly as I could my own impressions on the events of the past year, and their probable influence upon the future of our Association.

I cannot leave this subject without alluding to the earnest manner in which Dr. Mahomed, the secretary of this Committee, has devoted himself to the work. He was, I believe, one of the first to propose this plan of combined action, and the zeal and energy he has displayed cannot fail to be of the greatest service to the cause, and deserve our warmest thanks.

It now only remains for me to call upon the President-elect to fake the chair ; and in doing so, I congratulate you upon having secured the services of a man so deservedly popular; for though I have not the pleasure of an intimate personal acquaintance with Dr. Crowfoot, the name has been familiar to me for the last thirty years, and has been always associated with professional progress and professional honour.

\section{MESENTERIC AND OMENTAL CYSTS.}

\section{BY J. KNOWSLEY THORNTON, M.B., C.M.} Surgeon to the Samaritan Free Hospital.

THE short paper on the above subject by Mr. Spencer Wells, in the JourNaL of December 9 th, recalls a very interesting case of mesenferic tumour, upon which I operated in 1877 , but of which I have never published the details. I think it may be well, while the subject is be. forc the profession, to give the notes of it, and also of two casies of omental cyst which have occurred in my practice.

CASE.-S. M., aged 38, wife of a bank clerk, and mother of eight children, was placed under my care at the Samaritan Hospital in May 1877 , by Dr. Peskett of Leyton.

I found a large cystic tumour in the abdomen, and was able to diagnose extensive parietal and intestinal adhesions, and, by vaginal examination, a nodular mass in or closely connected with the left broad ligament. The nature of the tumour being doubtful, I tapped and removed thirteen pints of curious orange-coloured serum. The che. mical reactions of this fluid were rather those of a mixed ovarian and ascitic fuid, than of a pure ovarian or peritoneal fluid. The micro. scope did not aid the diagnosis, for I could find nothing but bloodcorpuscles, and a few small granular cells, so indistinct in outline, that I failed to draw them with the camera.

Careful examinations of the patient, made from time to time during the foilowing three weeks, led to the following diagnosis, entered in the case-book on June 12th: "A thin-walled flaccid cyst, with some solid masses, which can be distinctly felt per vaginam in the left broad ligament. I cannot feel at all sure whether it is an actual cyst, or only an encysted collection of fluid amongst the intestines, omentum, and mesentery. If it is the latter, it must be nearly a perfect cyst, as both flanks are clear, and changes of position vary the dulness but little."

An exploratory operation was decided upon, end performed on the following day. A very thin cyst, with unusually large veins in its anterior wall, was separated with difficulty from extensive adhesions to 